MEDICINE AND THE LAW

\title{
Surrogacy commissioning fathers and HIV
}

\author{
D W Jordaan \\ Donrich Jordaan is an advocate, member of the Pretoria Bar; and research fellow, Department of Jurisprudence, College of Law, University of South Africa
}

Corresponding author: D W Jordaan (mail@donrichjordaan.law.za)

Surrogacy is not regulated by a single legal instrument only, nor is confirmation of a surrogacy agreement by the High Court an unqualified green light for the surrogacy process to proceed. In the context of the HIV status of the commissioning father, whose gametes are to be used for the conception of the child in pursuance of a surrogacy agreement, the intended in vitro fertilisation of the surrogate mother may only take place on condition that the commissioning father, and his semen, have been tested for HIV; that he has consented to his HIV status being made available to the surrogate mother, and if he is HIV-positive, that sperm washing will be used to minimise the risk of infection and that the surrogate mother has been informed of his HIV status, and given her informed consent.

S Afr Med J 2014;104(1):12-13. DOI:10.7196/SAMJ.7498

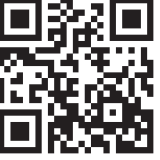

A person's HIV status is highly private, mainly due to the way in which it is generally transmitted and the lack of a cure. ${ }^{[1]}$ In $N M$ and Others $v$. Smith and Others, the Constitutional Court held that 'an individual's HIV status deserves protection against indiscriminate disclosure due to the nature and negative social context the disease has, as well as the potential intolerance and discrimination that result from its disclosure. ${ }^{[2]}$

Our courts have recognised the moral and legal duty of healthcare practitioners to keep their patients' HIV status confidential. ${ }^{[3]}$ However, this duty is not absolute and both the Health Professions Council of South Africa ethical rules ${ }^{[4]}$ and the South African Medical Association guidelines ${ }^{[5]}$ provide for disclosure of a patient's HIV status to their intimate partner by a healthcare practitioner under certain circumstances.

Consider the following: a surrogacy agreement has been confirmed by the High Court in terms of which the gametes of a certain HIVpositive commissioning father must be used. What is the legal duty of the responsible healthcare practitioners with regards to informing the surrogate mother of the HIV status of the commissioning father, or keeping this confidential? The answer is not found in a single legal instrument, but requires consideration of several legal rules.

This analysis is limited to the specific parameters of this question and the conclusions should not be applied outside these parameters.

\section{Surrogate motherhood: Relevant statutes}

Chapter 19 of the Children's Act ${ }^{[6]}$ is dedicated to surrogate motherhood. It deals with aspects such as the criteria that prospective commissioning parents and prospective surrogate mothers must fulfil, confirmation of the surrogacy agreement by the Court, and the enforceability of such an agreement. Regarding the artificial fertilisation of a surrogate mother in the execution of a surrogacy agreement, the Children's Act ${ }^{[6]}$ explicitly refers to the National Health Act. ${ }^{[7]}$ In 2012, the Minister of Health made the Regulations Relating to Artificial Fertilisation of Persons ${ }^{[8]}$ in terms of the National Health Act. The Regulations apply to all cases of artificial fertilisation of persons, including the artificial fertilisation of surrogate mothers in pursuance of surrogate motherhood agreements.
According to the Regulations, a 'gamete donor' is the person whose gametes are to be used for artificial fertilisation, and a 'recipient' is the woman who is to be artificially fertilised. ${ }^{[8]}$ The Regulations specifically define a 'surrogate' as a species of recipient ${ }^{[8]}$ therefore the 'commissioning father' whose sperm are to be used for the conception of the child in pursuance of a surrogacy agreement would be a species of gamete donor.

\section{Legal duties created by the Regulations} Important in the surrogacy process is the 'competent person', who is defined in relation to artificial fertilisation as a person registered as such in terms of the Health Professions Act, (Act No. 56 of 1974) who is: $(i)$ a medical practitioner specialising in gynaecology with training in reproductive medicine; or (ii) a medical scientist, medical technologist or clinical technologist with training in reproductive biology and related laboratory procedures. ${ }^{[8]}$

The first relevant legal duty created by the Regulations is that the commissioning father may not donate his sperm on his own volition without the involvement of a competent person in the donation process: 'Removal or withdrawal and storage of gametes: 3(1) No person, except a competent person, may remove or withdraw a gamete or cause a gamete to be removed or withdrawn, from the body of a gamete donor for the purpose of artificial fertilisation. ${ }^{[8]}$

This provision aims to ensure that the artificial fertilisation is done within the Regulations' regulatory framework. The Regulations further provide that, before the commissioning father may donate his sperm, the involved competent person must first:

- confirm that the commissioning father has on two occasions, not more than three months apart and one month before the intended donation, undergone medical tests for HIV and a semen analysis ${ }^{[8]}$

- obtain the commissioning father's informed consent that the results of these tests may be made available to the surrogate mother and the competent person who will perform the artificial fertilisation on the surrogate mother. ${ }^{[8]}$

Only after successfully performing these actions may the donation take place. Hereafter the involved competent person has a legal duty to make the results available to the surrogate mother ${ }^{[8]}$ Making information available to a person can entail its direct communication. 
It can also entail that the person is informed of the existence of the information, which should be made readily accessible and the person informed of how to access it. At a minimum, the Regulations require the involved competent person to inform the surrogate mother that the commissioning father's gamete donor file is available for her information.

The Regulations are clear that if the commissioning father's sperm has not been donated according to the Regulations, his sperm may not be used for the artificial fertilisation of the surrogate mother ${ }^{[8]}$ Thus the competent person who is to perform the in vitro fertilisation (IVF) on the surrogate mother must ensure that all the legal rules of the Regulations have been complied with before proceeding - even if this competent person was not involved with the donation of the sperm. Thus the competent person who is to perform the IVF on the surrogate mother must have a copy of the commissioning father's gamete donor file, and verify that it has been documented that the commissioning father has, within the prescribed timeframes, been tested for HIV, his semen has been analysed for HIV, and he has given his informed consent to the results being made available to the surrogate mother; and that the results have been received and have been made available to the surrogate mother.

\section{Legal duties at common law}

In the context of making the results available, further legal rules become relevant, namely our common law, as developed by case law, regarding consent to medical treatment.

The rule of informed consent states that a healthcare professional must warn a patient of all the material risks of the intended medical treatment, and that the patient must understand such risks but still consent to undergoing the intended medical treatment. This raises the question regarding the risks involved for the surrogate mother should the commissioning father be HIV-positive. In such a situation, it is assumed that sperm washing (to eliminate the chances of HIV infection ${ }^{[9-13]}$ ) would be utilised to minimise the chance of infection of the surrogate mother.

However, in the locus classicus of informed consent, Castell v. De Greef, ${ }^{[14]}$ the Court expressed itself in favour of a patientorientated approach ${ }^{[14]}$ to determining the materiality of the risks involved in the intended medical treatment, and hence whether the healthcare professional has a legal duty to warn a patient of such a risk. Accordingly, the Court held that a risk is material if, in the circumstances of the particular case, a reasonable person in the patient's position, if warned of the risk, would be likely to attach significance to it; or the medical practitioner is or should reasonably be aware that the particular patient, if warned of the risk, would be likely to attach significance to it.

I suggest that the reasonable surrogate mother would attach significance to the risk of HIV infection, even if statistically reduced to virtually zero by sperm washing. This is because of the life-threatening nature of HIV infection and associated negative emotions. This has been recognised by the Constitutional Court, which held in NM v. Smith that: 'There is nothing shameful about suffering from HIV/ AIDS. HIV is a disease like any other; however, the social construction and stigma associated with the disease make fear, ignorance and discrimination the key pillars that continue to hinder progress in its prevention and treatment. These pessimistic perceptions persist to fuel prejudice towards people living with HIV/AIDS. ${ }^{[2]}$

Accordingly, the competent person who is to perform the IVF on the surrogate mother has a legal duty to disclose the commissioning father's positive HIV status to the surrogate mother, and to explain to her the risks of HIV infection within the context of the utilisation of sperm washing and this technique's track record of safety.

\section{The surrogate mother's dignity}

In our constitution the value of autonomy is central..$^{[2,15]}$ Accordingly, the competent person cannot simply decide on behalf of the surrogate mother that the use of sperm washing will render non-material the commissioning father's HIV-positive status. The surrogate mother should make this decision. Whether the risk of HIV infection materialises or not (and gives rise to a medical negligence claim) is a secondary consideration. The primary consideration is the disregard by the competent person of the surrogate mother's autonomy. Such disregard of the surrogate mother's autonomy is belittling and she may feel insulted. Thus, irrespective of whether infection occurs or not, should the competent person omit to obtain the surrogate mother's informed consent regarding the commissioning father's HIV-positive status, such omission would constitute an infringement of her dignity, which is a crime and cause of action for a civil claim.

\section{Conclusion}

A single act (including an omission) - especially in the medical field - may be regulated by many legal rules. Therefore, in the context of this article, the fact that the High Court has confirmed a surrogacy agreement does not render the other layers of legal rules irrelevant.

\footnotetext{
1. Le Roux-Kemp A. HIV/AIDS, To Disclose or not to Disclose: That is the Question. Potchefstroom Electronic Law Journal 2013;16(1):200-239. [http://dx.doi.org/10.4314/pelj.v16i1.7]

NM and Others v. Smith and Others [2007] (5) SA 250 (CC).

2. NM and Others v. Smith and Others [2007] (5) SA 250 (CC).
3. Jansen van Vuuren and Another NNO v. Kruger [1993] (4) SA 842 (AD).

3. Jansen van Vuuren and Another NNO v. Kruger [1993] (4) SA 842 (AD).

Health Professions Council of South Africa. Guidelines for Good Practice in the Health Care Professions: Ethical Guidelines for Good Practice With Regard to HIV. Booklet 11. Pretoria: HPCSA, 2008. http://www.hpcsa.co.za/downloads/conduct_ethics/rules/generic_ethical_rules/booklet_11_ hiv.pdf (accessed 22 November 2013).

5. South African Medical Association. Ethical and Human Rights Guidelines on HIV: A Manual for Medical Practitioners of South Africa (2001). http://wwwl.chr.up.ac.za/undp/domestic/docs/ policies_03.pdf (accessed 22 November 2013).

6. South African Government. Children's Act No. 35 of 2008. Pretoria: Government Printer, 2008.

7. South African Government. National Health Act No. 61 of 2003. Pretoria: Government Printer, 2003.

8. National Department of Health. Regulations Relating to Artificial Fertilisation of Persons. Government Notice R175/2012. http://wwwdoh Relating to Artificial Fertilisation of Persons. Government Notice R17

9. Bujan L, Hollander L, Coudert M, et al. Safety and efficacy of sperm washing in HIV-1-serodiscordan 9. Bujan $\mathrm{L}$, Hollander $\mathrm{L}$, Coudert $\mathrm{M}$, et al. Safety and efficacy of sperm washing in $\mathrm{HIV}-1$-serodiscordant
couples

2007;21(14):1909-1914. [http://dx.doi.org/10.1097/QAD.0b013e3282703879]

10. Hanabusa $\mathrm{H}$, Kuji $\mathrm{N}$, Kato $\mathrm{S}$, et al. An evaluation of semen processing methods for eliminating HIV-1. AIDS 2000;14(11):1611-1616.

11. Nicopoullos JD, Almeida P, Vourliotis M, Gilling-Smith C. A decade of the United Kingdom spermwashing program: Untangling the transatlantic divide. Fertil Steril 2010;94(6):2458-2461. [http:// dx.doi.org/10.1016/j.fertnstert.2010.03.074

12. Savasi V, Ferrazzi E, Lanzani C, et al. Safety of sperm washing and ART outcome in 741 HIV-1serodiscordant couples. Hum Reprod 2006;22(3):772-777. [http://dx.doi.org/10.1093/humrep/del422]

13. Semprini AE, Macaluso M, Hollander L, et al. safe conception for HIV-discordant couples: Insemination with processed semen from the HIV-infected partner. Am J Obstet Gynecol 2013;208(5):402.e1-402. e9. [http://dx.doi.org/10.1016/j.ajog.2013.02.009]

14. Castell v. De Greef [1994] (4) SA 408 (C)

15. Barkhuizen v. Napier [2007] (5) SA 323 (CC)
}

Accepted 16 September 2013 